\title{
Globalização e Inconversibilidade Monetária
}

\author{
RICARDO CARNEIRO*
}

Globalization and monetary inconvertibility. The central hypothesis of this article is that in the context of globalization, monetary inconvertibility is a crucial problem of peripheral countries. It begins with a brief review of the debate from a historical point of view and then stresses the contemporary opposite's views on the fragility of financial system of emerging countries: the original sin and the debt intolerance hypothesis. Despite of supporting the first one, the article goes further and explores the domestic implication of inconvertibility. It criticizes the jurisdicional uncertainty proposition showing that an inherent flaw in the store of value of emerging market currencies, derived from original sin is the main reason for de facto inconvertibility and underdevelopment of domestic financial system of these countries.

Keywords: Globalization; convertibility; exchange rate volatility; interest rate volatility; financial deepening.

JEL Classification: O110.

... pensei que não existe nada menos

material que o dinheiro, já que qualquer moeda é, a rigor, um repertório de futuros possiveis.

O dinheiro é abstrato, repeti, o dinheiro é tempo futuro.

Jorge Luis Borges, O Zahir

\section{INTRODUÇÃO}

Diz-se que uma moeda é inconversível se não possui aceitação no âmbito internacional ou, mais propriamente, quando não desempenha nesse plano nenhuma

\footnotetext{
* Trabalho desenvolvido no âmbito do projeto temático "O Brasil e a periferia na era da globalização: inconversibilidade monetária, atraso produtivo, regimes de políticas econômicas e desenvolvimento" financiado pela FAPESP. O autor agradece os comentários de Luiz Gonzaga Belluzzo, Antonio Carlos Macedo e Silva, Daniela Prates, Marcos Antonio Macedo Cintra e André Biancarelli. Professor do Instituto de Economia e pesquisador do Centro de Estudos de Conjuntura e Política Econômica da Unicamp. E-mail: carneiro@eco.unicamp.br. Submetido: Fevereiro 2006; Aprovado: Junho 2007.
} 
das funções clássicas da moeda: unidade de conta, meio de pagamento ou reserva de valor. Assim, por exemplo, não há cotações internacionais de mercadorias em moedas inconversíveis, nem elas servem de moeda de denominação de contratos mercantis ou financeiros. Muito menos, denominam ativos financeiros de reserva; privados ou de bancos centrais. A noção de inconversibilidade monetária, todavia, não tem se constituído num objeto de estudo privilegiado do mainstream contemporâneo no qual aparece tratada parcialmente sob o título de original sin, debt intolerance, ou, ainda, currency mismatch. De maneira diversa, ela ganha o estatuto de questão crucial nas abordagens da economia política internacional, por meio da noção de hierarquia de moedas no âmbito do sistema monetário internacional.

A inconversibilidade tem sido, em graus variáveis, um atributo das moedas dos países periféricos. Nas versões mais brandas elas perdem suas funções no plano internacional, mas as mantêm, integral ou parcialmente, no âmbito doméstico. Nos casos mais radicais ocorre a substituição monetária, no plano nacional, extinguindo-se a moeda local. Assim, se no contexto internacional uma moeda inconversível não desempenha nenhuma das funções monetárias essenciais, no nacional, a inconversibilidade se manifesta por meio da cisão de suas funções, com a perda parcial do caráter de reserva de valor. Nesse domínio, vale dizer, enquanto veículo de expressão do valor de ativos e passivos, a moeda doméstica é substituída parcialmente por uma divisa estrangeira. Na América Latina, essa dimensão da inconversibilidade assumiu, em distintos países e em graus variáveis, a forma de dolarização de preços e contratos, em alguns casos, com a completa substituição da moeda local.

Quando as moedas locais mantêm, ao menos parcialmente, no âmbito doméstico as suas funções, há duas manifestações imediatas da sua insuficiência enquanto de reserva de valor: as altas taxas de juros, e a ausência de financiamento de longo prazo, em bases privadas e voluntárias, por meio de créditos ou títulos de dívida, nela denominados. Isto traduz a indisposição dos agentes econômicos em aceitar posições mais ilíquidas nessas moedas, expressando desse modo grande incerteza quanto ao valor futuro de débitos ou créditos. A forma pela qual esse problema foi enfrentado nas economias periféricas não seguiu um padrão único. Nos casos de maior êxito, a estabilidade monetária permitiu o desenvolvimento de um sistema de financiamento de longo prazo. Como regra geral, envolveu algum tipo de direcionamento dos fluxos financeiros domésticos.

A literatura recente do mainstream tem tratado do tema da inconversibilidade, destacando aquilo que julga ser sua principal implicação para os países periféricos: o currency mismatch, ou seja, o desequilíbrio patrimonial, decorrente de estruturas ativas e passivas denominadas em moedas distintas, ocasionado por flutuações recorrentes das taxas de câmbio. Esse artigo procura debater o assunto, recuperando também, nos termos do mainstream, a controvérsia sobre os determinantes do descasamento de moedas, confrontando a hipótese do original sin com a do debt intolerance.

Porém, o artigo não se restringe aos termos desse debate. Embora se alinhando com a hipótese do original sin, procura ir além e apontar implicações mais 
radicais da inconversibilidade monetária, num contexto de progressiva abertura financeira, para os países periféricos e, em especial, para o Brasil. O destaque é para a instabilidade macroeconômica, e suas conseqüências para o aprofundamento financeiro e a não constituição de um sistema de financiamento de longo prazo e, ainda, para o impedimento do desenvolvimento de formas superiores de organização capitalista, em razão da incapacidade da moeda local em servir como instrumento de centralização de capitais na esfera patrimonial. Em suma, propugna-se uma ampliação da noção de inconversibilidade monetária cujas conseqüências vão além das implicações decorrentes do efeito riqueza (currency mismatch) e caminham na direção de considerá-la como obstáculo decisivo ao desenvolvimento.

\section{O DEBATE CONTEMPORÂNEO}

A discussão a respeito da hierarquia de moedas no sistema monetário internacional, e da inconversibilidade, transcende o período da globalização e as questões propriamente econômicas. Ela remete, por exemplo, às controvérsias em torno da tese da estabilidade hegemônica desenvolvida inicialmente por Waltz (1959), e retomada no âmbito da economia política internacional por Gilpin (1971) e Kindleberger (1973), segundo a qual haveria a necessidade da existência de um centro de gravidade político para dotar o sistema econômico internacional de estabilidade. Deste centro ou país central emanariam as instituições e, dentre elas, a moeda, capazes de fazer face à instabilidade intrínseca dos mercados e à competição interestatal exacerbada.

$\mathrm{Na}$ avaliação que faz da controvérsia, Scandiucci Filho (2000) destaca que a crítica mais consistente à teoria da estabilidade hegemônica está fundada na contestação do privilégio exclusivo, atribuído por esta teoria à dimensão política ou interestatal na conformação das relações internacionais, subestimando a sua dimensão propriamente econômica, vale dizer, o papel dos agentes privados, tais como bancos, empresas, investidores institucionais etc. Essa lacuna da teoria se veria aguçada na etapa da globalização do capitalismo, durante a qual o papel dos agentes privados na conformação das relações internacionais teria caráter dominante. Em favor da teoria da estabilidade hegemônica se pode alegar que ela foi concebida durante o período de maior regulação do capitalismo, durante o qual os fluxos financeiros domésticos e internacionais encontravam-se fortemente disciplinados. Nesse contexto a dimensão propriamente política ou interestatal das relações internacionais ganhou preeminência ante a esfera propriamente econômica.

$\mathrm{Na}$ análise das relações internacionais, na era da globalização, Fiori (1999) destaca a hierarquia monetária, analisando-a a partir de uma dupla determinação, a política ou estatal, e a econômica ou dos mercados. Utiliza-se da análise de Karl Polanyi relativa à formação da ordem internacional liberal do final do século XIX (padrão-ouro), ressaltando as seguintes similitudes com a ordem da globalização: a constituição da hierarquia internacional com base em critérios econômicos bem definidos (tamanho, profundidade dos mercados etc.); relação oposta entre Estado 
(política) e economia (dinheiro) de acordo com a posição na hierarquia monetária, vale dizer, preeminência do primeiro naqueles países mais bem situados na hierarquia mundial e da segunda naqueles pior situados.

Partindo de paradigma semelhante, Tavares e Belluzzo (2004) discutem a formação das várias ordens internacionais e da hierarquia de países dentro delas, como produto de um duplo movimento: o do capital (economia) e o dos Estados nacionais (política). Esses movimentos não são necessariamente convergentes, nem complementares, mas no período da globalização a sua convergência produziu o domínio americano fundado no poder político-militar e na superioridade econômico-financeira traduzidos na consolidação do dólar como a moeda-reserva internacional. No extremo oposto da hierarquia estariam as moedas inconversíveis, caracterizadas como aquelas que têm demanda nula, enquanto ativo de reserva, por parte de agentes de terceiros países.

A inconversibilidade monetária, embora intrinsecamente associada à constituição da economia internacional, ganha destaque no ambiente crescentemente liberalizado no qual as transações mercantis são largamente sobrepujadas pelas financeiras. Tomando como referência o marco histórico da globalização, Cohen (1998) sugere uma crescente desterritorialização do dinheiro com a contrapartida da perda de relevância do dinheiro nacional ou, pelo menos, da maioria das moedas, que passam a obedecer no plano internacional a uma rígida hierarquia.

No contexto da globalização, Cohen (1998) advoga que subjacente à desterritorialização forma-se uma dinâmica de concorrência e não de cooperação ou convivência entre as moedas, dando origem a uma rígida pirâmide monetária na qual as moedas do topo têm reforçadas suas prerrogativas internacionais enquanto as da base correm o risco permanente de ser substituídas, até mesmo nas suas funções domésticas.

A necessidade de uma moeda internacional adviria das economias de escala e das reduções de custos de transação daí decorrentes. As candidatas a exercerem essas funções seriam aquelas moedas capazes de reunir três prerrogativas distintas: estabilidade, definida por taxa de inflação recorrentemente baixa; pequeno risco de perda de capital associado a liquidez e profundidade dos mercados financeiros domésticos; rede (networks) disseminada em razão do tamanho da economia e de suas relações comerciais.

O ponto forte na argumentação de Cohen (1998) é a relação dialética estabelecida entre a internacionalização monetária (currency internationalization), privilégio de algumas poucas moedas, e a substituição monetária (currency substituition) atributo das moedas frágeis. Assim, o avanço de algumas moedas no plano internacional e a sua consolidação no topo da pirâmide tem como contrapartida outro processo de substituição monetária, parcial ou total, na sua base.

No âmbito do mainstream, uma das suas variantes, como por exemplo Eichengreen, Hausmann e Paniza (2003), Eichengreen e Hausmann (2005), trata a questão da inconversibilidade por meio do assim chamado pecado original (original sin). Esse é definido como a incapacidade de um país endividar-se na sua própria moeda, no mercado internacional. Inicialmente, o conceito dizia respeito 
à ausência de endividamento ou emissão de títulos de longo prazo, na própria moeda do país, no seu espaço nacional. Isto é, a questão essencial era a da instabilidade ou incerteza quanto ao valor da moeda no plano doméstico, concedendo-se importância central à inflação. Assim, na ausência de estabilidade de preços era impossível emitir obrigações de longo prazo numa moeda qualquer no espaço nacional e, muito menos, se endividar nessa moeda no plano internacional.

De acordo com os autores, a experiência histórica demonstrou o caráter parcialmente equivocado dessa tese. Isto porque a estabilidade de preços conseguida por muitos países periféricos, após os anos 1990, tornou viável a emissão de obrigações de longo prazo nos mercados domésticos. Essa mudança, contudo, não se traduziu na possibilidade de endividar-se na própria moeda nos mercados internacionais. Evidenciou-se, assim, a existência de um atributo particular da inconversibilidade monetária, não atinente à dimensão doméstica, ou à estabilidade do valor interno da moeda, mas ao seu valor externo, vinculado a fatores intrínsecos ao sistema monetário internacional e à sua organização. Dessa perspectiva, a inconversibilidade seria uma característica permanente dos países periféricos, perpassando as várias ordens monetário-financeiras internacionais e assumindo maior ou menor importância de acordo com o grau de liberalização dos fluxos de capitais.

Segundo os autores citados, a explicação para a existência de moedas portadoras do pecado original funda-se na presença de uma hierarquia de moedas nos sistema monetário internacional. Essa hierarquia tem por base o tamanho ou o peso de cada economia no âmbito internacional. Utilizando a idéia dos custos de transação e das externalidades, os autores afirmam ser mais vantajoso para os detentores de riqueza, em países menores, diversificarem portfolios em direção às moedas de maior peso do que o contrário.

Do ponto de vista dos portfolios privados, os incentivos para diversificação em termos de moeda são assimétricos, pois há custos de transação que serão tão maiores quanto menor for o peso da moeda em questão nos vários tipos de transações internacionais. Ao mesmo tempo, sair das moedas mais fortes em direção às mais fracas implicaria perda de externalidades. Essas características traçariam uma linha divisória entre moedas conversíveis e inconversíveis.

$\mathrm{Na}$ argumentação desenvolvida por Eichengreen e Hausmann (2005), a definição da linha divisória entre moedas conversíveis e inconversíveis tem no tamanho dos mercados financeiros um critério crucial. Daí a presença dos centros financeiros internacionais, além dos grandes países, como emissores de obrigações e haveres nas suas respectivas moedas. Como se sabe, vários desses centros possuem economias diminutas e relações comerciais pouco expressivas. Assim, em países com mercados financeiros mais profundos os investidores globais podem ampliar o grau de diversificação dos portfolios e reduzir riscos. O mesmo não ocorre com países de mercados financeiros menos profundos, pois nesse caso o ganho inicial de diversificação em termo de moeda é anulado pela possibilidade de autocorrelação de preços de ativos.

Apesar de admitirem a existência da inconversibilidade, autores como Bordo e Flandreau (2001) defendem ponto de vista distinto para a sua explicação. 
Segundo eles é a instabilidade do valor interno que se transmite ao valor externo, retirando dessas moedas o estatuto de reserva de valor, no plano internacional. A questão essencial seria a da inexistência, nas economias periféricas, de aprofundamento financeiro. Isto implicaria uma ausência de compromisso da política econômica com a baixa inflação, vale dizer, com a estabilidade do valor interno da moeda, o que por sua vez se transmitiria à taxa de câmbio, ou valor externo da moeda, tirando-lhe credibilidade. Como conseqüência, a incapacidade de emitir dívida no plano internacional nas moedas inconversíveis teria origem doméstica e não internacional.

No âmbito das interpretações fundadas na idéia das falhas domésticas como elementos explicativos da fragilidade das moedas periféricas, destacam-se duas outras vertentes. A primeira delas ganha corpo no conceito de debt intolerance desenvolvido por Reinhart, Rogoff e Savastano (2003). Segundo esses autores, a excelência das políticas e instituições domésticas e o histórico de default no plano internacional definiriam a qualidade da moeda do país periférico. Como regra geral, as classificações de risco e os limites ao endividamento estariam associados tanto ao histórico de default, como ao de inflação, definindo o debt intolerance de cada país. A linha de argumentação é bastante clara, procurando negar integralmente a noção do original sin. Assim, tanto o default no plano externo como a inflação no interno seriam responsáveis pela baixa credibilidade da moeda como reserva de valor.

$\mathrm{O}$ argumento do debt intolerance como hipótese para a fragilidade das moedas periféricas é claramente insuficiente. Ele constitui uma aproximação razoável para as distinções quantitativas entre as moedas, mas não para as de maior relevância, as qualitativas. Por exemplo, apesar de algumas moedas de países periféricos possuírem classificações de risco semelhantes àquelas de países centrais, isto não constitui condição suficiente para emissão de dívidas denominadas nessas moedas nos mercados globais. De modo semelhante, apesar de haver uma discrepância significativa entre as classificações de risco das moedas periféricas, todas, sem exceção, partilham do pecado original.

A proposta de classificar as moedas periféricas de acordo com o seu histórico de default, interno e externo, constitui uma tentativa de inverter o problema central dessas moedas. É muito mais razoável admitir que o default resulte da combinação entre pecado original e caráter pró-cíclico acentuado dos mercados internacionais, financeiros e de commodities, que induzem as economias periféricas a níveis de endividamento e de currency mismatch insustentáveis. A associação entre ciclos de preços de commodities, e financeiros, tendo como resultado níveis elevados de endividamento, valorização das moedas periféricas e sucessivas crises cambiais detonadas pela reversão dos ciclos globais, constitui um padrão recorrente de comportamento dos países periféricos desde a vigência do padrão-ouro, como analisado por Medeiros (2006). O plano interno seria, no mais das vezes, subordinado a essa dinâmica global.

Uma segunda vertente do mainstream, atribuída a Goldstein e Turner (2004), centra-se na discussão dos efeitos do original sin, tomando-o como um dado, pois 
reconhece a sua existência, mas nega que o currency mismatch seja sua decorrência inevitável, podendo ser eliminado por políticas locais. Para esses autores, os efeitos decorrentes da incapacidade dos países periféricos em emitir dívida em suas moedas nos mercados internacionais, sintetizados no currency mismatch, são, em última análise, resultantes da qualidade das políticas e instituições locais. Essas deveriam preocupar-se em desenvolver internamente as condições para superação do problema. Vale dizer, evitar a formação, em escala significativa, das posições descasadas. Isso incluiria políticas macroeconômicas críveis - que assegurassem patamares recorrentemente baixos de inflação - e indutoras do desenvolvimento financeiro doméstico; políticas regulatórias e prudenciais para evitar exposição excessiva em moeda estrangeira; e aquelas destinadas a desenvolver o mercado de capitais locais, reduzindo de maneira significativa a dependência de poupança externa.

A rigor, a disputa dessa concepção com a do original sin se dá na negação da primeira enquanto restrição incontornável. Não desconhece o problema, o original sin, nem os seus efeitos, o currency mismatch, apenas advoga a centralidade das dimensões domésticas com ênfase nas políticas necessárias para a determinação do volume de posições descasadas e seu gerenciamento. Assim, as políticas sugeridas não vão na direção de superar os problemas no plano internacional, pois ao que tudo indica ele é irremovível, mas de eliminá-lo no plano doméstico. O problema é que essa tese ignora duas dimensões essenciais e interligadas da questão: a centralidade dos ciclos de liquidez global na determinação dos fluxos de capitais e os custos domésticos, principalmente fiscais, de controlar o currency mismatch.

Em resumo, as abordagens do mainstream dividem-se quanto às razões, distintas e opostas, para a inconversibilidade. Numa vertente temos a tese para a qual a sua explicação estaria na hierarquia de moedas no sistema monetário internacional. Noutro pólo, as teses que enfatizam razões domésticas, incluindo o histórico de default e a não credibilidade de políticas. Para essas abordagens seria a qualidade das políticas e das instituições domésticas os principais determinantes da instabilidade do valor interno da moeda, atributo que terminaria por transmitir ao seu valor externo, tornando-a uma reserva de valor pouco crível.

A questão essencial tratada nas duas abordagens é, portanto, a das razões que impedem as moedas inconversíveis em transformarem-se em reservas de valor. A tese do pecado original parece ser uma explicação mais robusta ao apontar um elemento de bloqueio ao desenvolvimento dessa função nas moedas periféricas, oriunda da ordenação do sistema monetário internacional, atribuindo à hierarquia de moedas o caráter determinante, em última instância, dessa atrofia. As demais interpretações fazem, em maior ou menor grau, o percurso inverso.

\section{A variante brasileira}

Uma das contribuições mais relevantes ao debate da inconversibilidade no âmbito do mainstream no Brasil é de autoria de Arida (2003a; 2003b). O argumento central dos artigos é o de que é imprescindível fazer do real uma moeda 
plena e legalmente conversível, como forma de reduzir as elevadas taxas de juros vigentes no país e assegurar o seu estatuto de reserva de valor.

Segundo este autor, a razão histórica para que a conversibilidade tenha sido restrita deveu-se à incapacidade da moeda nacional de exercer a função de reserva de valor, no plano doméstico, devido à inflação crônica, motivo parcialmente suprimido pela estabilidade de preços obtida após 1994. Superado esse problema, ou seja, o da qualidade da reserva de valor no âmbito doméstico, a inconversibilidade passou a ser uma restrição jurídica fundada no temor de que a supressão dos entraves à conversibilidade implicasse uma transformação de parcela expressiva da poupança doméstica em aplicação no exterior. Segundo o autor, esta seria uma abordagem viesada, pois se a eliminação de restrições fosse percebida como segura e permanente, implicaria uma oferta ampliada de divisas por parte de nãoresidentes, referendando o caráter de boa reserva de valor da moeda local.

Embora reconheça que a liberalização irrestrita pode ocasionar volatilidade excessiva dos fluxos de capitais e bolhas especulativas, conduzindo a taxas de câmbio excessivamente valorizadas ou desvalorizadas, como, aliás, tem ocorrido nos últimos anos, o autor nega que a restrição à conversibilidade possa minimizar o problema. Para evitá-los, sugere que o Banco Central atue diretamente no mercado de câmbio, comprando e vendendo divisas, e que se utilize, quando necessário, de uma tributação dos fluxos de capitais com alíquota uniforme. O autor chega a afirmar que o fato de o Banco Central atuar no mercado de câmbio por meio de substitutos da moeda estrangeira, tais como títulos indexados em dólar e operações no mercado futuro, apenas exacerba a desconfiança em relação à moeda nacional.

Ao discutir a formação da taxa de juros do país, o autor assume a hipótese de que a existência de ameaça à suspensão da conversibilidade introduz um prêmio adicional, além daquele relativo ao risco de crédito, cobrado pelos investidores estrangeiros. Assim, a taxa de juros, em dólar, seria composta pela taxa básica de juros na moeda reserva somada a um risco de país, o qual poderia ser decomposto em duas partes: o risco de crédito ou de default e o risco jurídico ou de racionamento de divisas. Com a eliminação deste último, a taxa de juros cairia, diminuindo o risco país, a taxa de juros em dólar e, por arbitragem, a taxa de juros em reais. Além da questão do patamar quantitativo dos juros o autor chama a atenção para o fato de que a remoção dos empecilhos à conversibilidade terminaria por eliminar também a noção de risco soberano. Ou seja, sendo a compra e venda de divisas integralmente livre existiriam apenas tomadores com distintos riscos de crédito.

Ao criticar a posição de Arida, que advoga ser a inconversibilidade da moeda em países periféricos, como o Brasil, resultado da inconversibilidade de direito (de jure), ou seja, da ausência de um marco legal estável capaz de assegurar de maneira permanente essa conversibilidade, Belluzzo e Carneiro (2004) assinalam que "a remoção de fato ou de direito das restrições à conversibilidade no plano doméstico não torna a moeda nacional uma referência ou uma reserva de valor no plano internacional. Num horizonte de tempo previsível, a nossa moeda não passará a denominar contratos, constituir-se em referência de preços e muito menos será demandada como ativo de reserva por terceiros países”. 
A rigor, a tese de Arida (2003a; 2003b) pretende reduzir a questão da inconversibilidade de uma moeda qualquer à ausência de restrições legais aos fluxos de capitais, seja no plano do acesso de não-residentes (inward transactions), seja no da saída de residentes (outward transactions). A conversibilidade irrestrita terminaria por transformar a moeda em reserva de valor. $\mathrm{O}$ autor despreza o argumento da qualidade diferenciada ou da hierarquia de moedas e, portanto, a idéia de que há elementos dificilmente superáveis ao estabelecimento da conversibilidade, não associados a seus aspectos legais. Vale dizer, a superação da inconversibilidade de jure não implicaria o estabelecimento da conversibilidade de fato.

$\mathrm{Na}$ discussão do caso brasileiro, a constatação da atrofia da função de reserva de valor da moeda local desdobra-se na sua incapacidade em fundar relações financeiras de longo prazo. Autores como Arida, Bacha e Lara-Rezende (2004) atribuem-na ao risco jurisdicional, ou seja, deslocam o diagnóstico ortodoxo da ausência de um mercado de financiamento de longo prazo dos aspectos macroeconômicos tradicionais, como o crowding out, e a instabilidade inflacionária, para determinantes microeconômicos. O risco jurisdicional seria resultante da discriminação contra os credores em geral. Ele se expressaria, por exemplo, nas medidas práticas contra a poupança financeira, tais como subindexação, confisco parcial e mudanças ad hoc do marco regulatório. No plano bancário, sua manifestação se exprimiria na baixa eficácia da legislação para a recuperação dos créditos em default cujo efeito prático seria o estímulo à inadimplência.

As consequiências do risco jurisdicional seriam: uma ampliação da preferência pela liquidez, com a concentração da poupança financeira nas formas mais líquidas; o aumento da preferência pelo consumo em detrimento da poupança; a transferência de poupança para o exterior para moedas de maior credibilidade ou a sua canalização para os ativos reais.

$\mathrm{O}$ argumento, portanto, é o de que o risco jurisdicional constituiria o principal determinante da perda da função de reserva de valor na moeda nacional ou, o que dá no mesmo, do elevado prêmio exigido pelos poupadores para assumirem posições de maior iliquidez nessa moeda. Segundo Arida, Bacha e Lara-Rezende (2004), uma evidência contundente seria o contraste entre a inexistência de um mercado de financiamento de longo prazo, no âmbito doméstico, e a sua existência na esfera internacional, cujo funcionamento se ateria a outro marco jurídico sem os vícios do mercado local. A rigor essa concepção é um desdobramento daquela desenvolvida por Arida (2003a; 2003b), relativa à inconversibilidade, a qual decorreria sobretudo da incerteza jurídica.

\section{UMA ABORDAGEM ALTERNATIVA}

Na caracterização da inconversibilidade a partir de uma perspectiva crítica, um ponto inicial a ser destacado é a existência, nas moedas inconversíveis, de uma fratura entre o valor interno da moeda (medido pelo valor monetário de uma cesta 
representativa de bens e serviços e a sua variação) e o seu valor externo (medido por uma taxa de câmbio com uma divisa-chave, ou o ouro e a sua respectiva variação). Por sua vez, o diagnóstico mais preciso sobre as razões da inconversibilidade exige uma discussão aprofundada sobre a incapacidade das moedas periféricas em se constituírem como reserva de valor, tanto no plano internacional como no doméstico. Assim, cabe examinar os motivos pelos quais, num regime internacional de ampla mobilidade de capitais, um ativo de emissão de país periférico, tanto denominado na sua moeda como na moeda reserva, em mercados locais ou internacionais, constitui uma frágil reserva de valor.

Uma hipótese pode ser aqui formulada: a de que a estabilidade de preços obtida no plano doméstico não se traduz necessariamente em estabilidade monetária, ou seja, a estabilização do valor interno da moeda não se transmite à estabilidade do valor externo da moeda, expresso na sua taxa de câmbio com as divisas centrais. Para uma parcela expressiva das moedas periféricas é exatamente a instabilidade do valor externo da moeda a razão essencial para a instabilidade de seu valor interno.

Para desenvolver este argumento deve-se partir dos riscos (de crédito, de preço e de mercado) inerentes à posse de ativos emitidos por um determinado país periférico.

Para ilustrar o problema vejamos inicialmente a formação da taxa de juros para esses países a partir da hierarquia de moedas. De acordo com Belluzzo e Carneiro (2004): "Num mundo marcado pela mobilidade de capitais e taxas de câmbio flutuantes, as (n-1) moedas do sistema podem ser hierarquizadas conforme seus riscos de crédito e prêmios de liquidez em relação à moeda reserva". Assim, o sistema internacional tem uma moeda global ou reserva, no caso o dólar, que por ser a moeda do sistema não tem prêmio de liquidez ou, dito mais rigorosamente, não possui risco de preço ante si própria. As demais moedas, além dos riscos de crédito particulares, os riscos-país, têm riscos de preço variável cuja magnitude depende da avaliação dos agentes a propósito das condições da sua conversão na moeda reserva, ou seja, da flutuação esperada da taxa de câmbio ante a moeda reserva.

A passagem anterior é crucial para caracterizar a noção de hierarquia de moedas. Há na ordenação dessas últimas, um componente essencial relativo à confiança diferenciada nelas depositadas. Essa se traduz na existência de um ativo sem risco de preço e que por isso mesmo exerce a função de moeda reserva. Além dos diferentes riscos de preço, a hierarquia de moedas se expressa por meio dos prêmios de risco adicionais, tais como os de crédito e os de mercado. Assim, olhado o sistema internacional a partir da moeda reserva, cada moeda particular para atrair fluxos de capitais ou para mantê-los paga sobre essa moeda reserva um prêmio de risco cujos componentes foram especificados acima. Assim, as moedas são inconversíveis não apenas por possuírem prêmios de risco mais elevados, expressão dos riscos de crédito, mas também pelo pecado original, o que confere ao risco de preço uma dimensão exacerbada. 


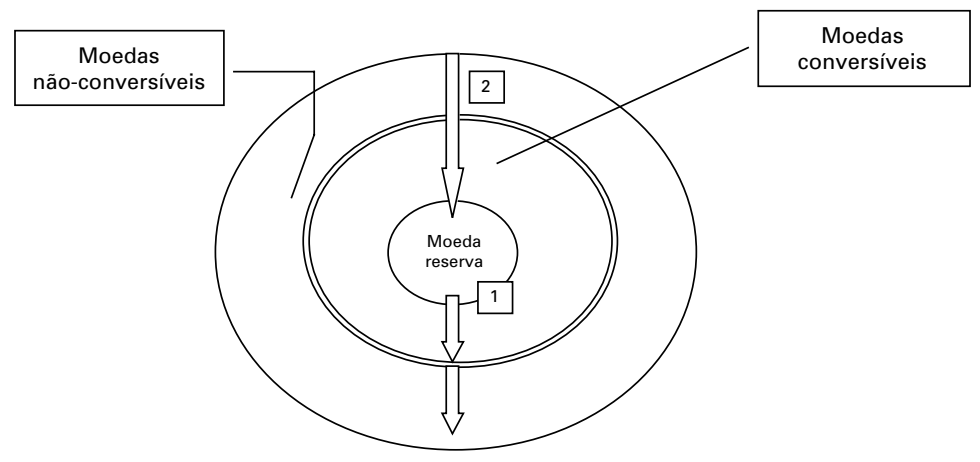

Na Figura 1, a hierarquia do sistema monetário internacional está representada, na sua dimensão qualitativa, pela existência de um núcleo composto pela moeda reserva e duas outras qualidades de moedas: as conversíveis e as inconversíveis. A moeda reserva, além de não ter risco de preço ante si própria, também possui o menor risco de crédito e emite o título considerado o risco zero do sistema global: os títulos do Tesouro americano de longa maturidade. Ademais, por possuir mercados financeiros mais desenvolvidos também se caracteriza pelo menor risco de mercado. De acordo com Serrano (2002), em razão dessas propriedades, a moeda reserva teria um estatuto peculiar no sistema monetário internacional: a capacidade de definir, de maneira unilateral, a taxa de juros básica desse sistema. Como assinalado por Belluzzo (1997), isto se deveria ao fato de que a moeda reserva se constitui na representação geral e abstrata da riqueza do sistema globalizado e, portanto, as condições de sua posse definem os parâmetros para a busca de outras formas de riqueza, incluindo as demais moedas do sistema.

$\mathrm{Na}$ Figura 1 também pode ser expresso o movimento dos capitais que saem da moeda reserva para as demais (seta 1). Esses, por se defrontarem com riscos mais elevados, nessa sua mobilidade, exigem também prêmios maiores para migrarem para outras moedas. A distinção entre as moedas conversíveis e inconversíveis estaria no peso desproporcional que assume, nessas últimas, a parcela dos prêmios de risco atribuíveis ao risco de preço decorrente da variabilidade das suas taxas de câmbio contra a moeda reserva. Por essa razão pode-se também entender o movimento inverso (seta 2) dos capitais que saem das moedas de pior qualidade para a moeda reserva e exigem prêmios de risco menores. Porém, nesse último movimento, há uma particularidade, qual seja, uma parcela da riqueza dos residentes em países de moeda inconversível buscará ativos em moeda reserva, independentemente da remuneração desses ativos, pelo fato mesmo de estarem em moeda reserva. Ou seja, a motivação é assimétrica segundo a origem-destino dos fluxos de capitais.

Por meio do Quadro 1 pode-se detalhar a análise da inconversibilidade monetária utilizando os prêmios de risco e, tomando em conta os diferentes mercados, moedas de denominação e distintos prazos dos ativos financeiros emitidos por 
um país periférico. Nos mercados internacionais para países da periferia, aqueles de maior proeminência são os de títulos emitidos, ou empréstimos concedidos, a país de moeda inconversível, denominado em moeda reserva ou, ao menos, conversível. Nesses mercados, a denominação em moeda inconversível existe, mas ocorre apenas em momentos particulares. Vale dizer, naqueles de maior liquidez, coincidentes com os auges dos ciclos financeiros. De acordo com Arida, Bacha e Lara-Rezende (2004), no caso brasileiro a existência desse mercado no âmbito internacional, em particular do segmento de longo prazo e denominado em moeda conversível, contraposto à inexistência do mercado local de títulos ou empréstimos de longo prazo e denominado em moeda doméstica, expressaria a centralidade do risco jurisdicional.

Há vários aspectos de grande relevância omitidos pelos autores na sua interpretação. $\mathrm{O}$ primeiro deles se refere à diferenciação entre haveres financeiros emitidos no mercado doméstico, denominados em moeda reserva e em moeda local. Os primeiros pagam taxas de juros menores e possuem prazos mais longos do que os segundos, diferença que só pode ser atribuída à moeda de denominação. Essa afirmação pode ser ilustrada pela constatação do diferencial de juros e prazos de títulos da dívida pública, quando parte dela era indexada à variação da taxa de câmbio. Aliás, a troca dessa parcela da dívida por outra denominada em moeda local, realizada entre 2003 e 2004, implicou não só redução de prazos dos títulos como o aumento da parcela indexada aos juros do overnight. Ou seja, a troca de moeda de denominação exacerbou os riscos da dívida pública.

$\mathrm{O}$ segundo aspecto ignorado refere-se ao fato de que os mercados internacionais para títulos de países de moeda inconversível pertencem, na sua maior parte, ao segmento de high yield. Há uma forte correlação entre a inconversibilidade monetária e as classificações de risco, bem como com a presença expressiva desses países no segmento sem classificação de risco (sub-investment graded). Os investidores são atraídos para esse nicho de mercado por conta dos altos rendimentos como contrapartida dos riscos mais elevados. Uma prova contundente dessa característica dos mercados para países emergentes é a sua alta correlação com aqueles mercados de títulos corporativos de pior qualidade nos EUA, o assim chamado mercado de junk bonds. Toda esta argumentação põe em relevo um ponto omitido pela argumentação de Arida, Bacha e Lara-Rezende (2004), qual seja, o de que os mercados de títulos e empréstimos de longo prazo para emergentes, na jurisdição internacional, existem, mas têm, na sua maioria, caráter de alto risco.

Quadro 1: Mercados financeiros e moeda inconversível

\begin{tabular}{|l|c|c|c|c|}
\hline \multirow{2}{*}{$\begin{array}{l}\text { Prazo } \\
\text { Mencado }\end{array}$} & \multicolumn{2}{|c|}{ Curto Prazo } & \multicolumn{2}{c|}{ Longo Prazo } \\
\cline { 2 - 5 } & Doméstico & Internacional & Doméstico & Internacional \\
\hline $\begin{array}{l}\text { Moeda Reserva } \\
\text { ou Conversível }\end{array}$ & $\operatorname{sim}$ & $\operatorname{sim}$ & $\operatorname{sim}$ & $\operatorname{sim}$ \\
\hline $\begin{array}{l}\text { Moeda Doméstica } \\
\text { Inconversível }\end{array}$ & $\operatorname{sim}$ & não & não & não \\
\hline
\end{tabular}


Pode-se contra-argumentar a partir das exceções, ou seja, que há diversos países cujas moedas são inconversíveis mas seus títulos soberanos não pertencem ao segmento de high yield. Essas moedas, sobretudo aquelas dos países da Ásia em desenvolvimento, obtêm por diversos expedientes uma conversibilidade virtual. O primeiro expediente é o lastreamento em moeda reserva, visível, por exemplo, nos elevados montantes de reservas líquidas, em dólar, de propriedade dos bancos centrais desses países, o que na prática reduz o risco de preço dessas moedas ao estabilizar a taxa de câmbio. O segundo, os altos montantes dos superávits em conta corrente que asseguram a manutenção desses elevados estoques de ativos em moedas-chave e cujo significado maior é a redução dos riscos de crédito. Conversibilidade virtual e menor risco de crédito retiram os títulos emitidos nessas moedas do segmento de alto rendimento mas não lhe redimem do pecado original.

A agregação dos três riscos explicita inequivocamente o pertencimento dos ativos emitidos por esses países no mercado internacional ao segmento de high yield, com as exceções referidas. Mas há um mecanismo circular de reforço a esse estado. Isso ocorre porque o fraco apelo desses ativos como reserva de valor, em contraste com os seus altos rendimentos, lhes confere o caráter de investimento especulativo. Isso quer dizer que os capitais alocados para a aquisição dos títulos emitidos por países periféricos têm comportamento mais volátil. Ademais, exatamente por estarem denominados em moeda de menor qualidade o valor e o rendimento desses títulos são mais sensíveis ao ciclo de liquidez internacional, sujeitando-se com mais intensidade aos sudden stops, típicos desses ciclos, ou ao seu padrão de feast and famine. A conseqüência é uma maior volatilidade do valor externo dessas moedas, ou seja, da sua taxa de câmbio com a moeda reserva.

A argumentação anterior pode ser também contestada à luz da crescente emissão de títulos por parte dos países emergentes denominados nas suas moedas, nos mercados globais, após 2005. O ponto central a ressaltar é que esta ocorrência não constitui, a rigor, uma novidade no mercado internacional de capitais. Ela tem sido, aliás, bastante comum nos auges dos ciclos de liquidez, como por exemplo em 1996/1997. O duvidoso é a sua permanência, como atesta a experiência histórica dos "mares do sul" às "tulipas holandesas". Faz parte também dessa exceção, configurada no auge do ciclo, o descolamento dos rendimentos dos países emergentes daqueles dos junk bonds.

No âmbito doméstico, o primeiro passo para analisar a razão da atrofia da dimensão reserva de valor da moeda nacional e da conseqüente inexistência dos mercados de crédito e de títulos de longo prazo, denominados na moeda local, refere-se à formação da taxa de juros. Nos mercados globalizados a regra de formação é a adição do risco-país ao risco zero do sistema, no caso a taxa de juros de títulos do Tesouro americano de maturidade correspondente. Para se chegar à taxa de juros doméstica, de acordo com o teorema da paridade descoberta da taxa de juros, adiciona-se a estes termos a expectativa de desvalorização cambial. 
Assim temos:

$\mathrm{i}=\mathrm{i}^{*}+\mathrm{RS}+\mathrm{VC},(1)$ onde:

$\mathrm{i}=$ taxa de juros básica em moeda local;

$\mathrm{i}^{*}=$ taxa de juros básica ou risco zero na moeda reserva;

$\mathrm{RS}=$ prêmio de risco soberano em moeda reserva;

$\mathrm{VC}$ = variação esperada da taxa de câmbio da moeda local, ante a moeda reserva.

Define-se pelo procedimento acima uma taxa de juros básica, relativa ao risco zero do sistema doméstico, a dos títulos públicos. Na maioria dos países de risco elevado, e particularmente no Brasil, essa taxa básica de juros tem um patamar bastante alto. Conforme assinalado por Hermann (2004), o valor elevado da taxa de juros de curto prazo inviabiliza o desdobramento de prazos no sistema financeiro em razão do prêmio de risco excessivo, implícito nessa operação. Seu argumento principal é o de que a baixa atratividade dos ativos de longo prazo deve-se principalmente à concorrência dos ativos de curto prazo, em particular dos títulos públicos de alta remuneração e liquidez. Assim, o elevado piso de juros do sistema financeiro doméstico, definido pelos títulos públicos, torna o custo do financiamento de longo prazo, tanto para o setor privado como público, proibitivo. Nessas circunstâncias, a ausência de um sistema de financiamento de longo prazo decorreria da impossibilidade de formação de uma curva de rendimentos (yield curve), cujo ponto inicial seria títulos de alta liquidez e rentabilidade. Embora a argumentação anterior esteja, na sua essência, correta, é necessário ir além e assinalar que o problema não está somente no alto patamar da taxa de juros, mas também na sua volatilidade.

Em contraposição à tese de Arida, Bacha e Lara-Resende (2004), para os quais tanto o alto patamar da taxa de juros com a inexistência de um sistema de financiamento de longo prazo devem-se ao elevado risco jurisdicional, propõe-se que essas características do sistema financeiro brasileiro estejam associadas à inconversibilidade da moeda e, por essa razão, aos elevados riscos implícitos para a intermediação financeira.

Dada a alta taxa de retorno dos títulos públicos de curto prazo e a sua volatilidade, uma operação de desdobramento de prazo trás implícito um risco elevado. A partir das taxas iniciais a agregação de um spread definirá taxas de juros ainda mais altas implicando maior risco em razão da seleção adversa. Com taxas básicas muito elevadas e voláteis torna-se impraticável a constituição de uma curva de rendimentos (yield curve) tanto para os títulos públicos como para os demais papéis.

É necessário considerar ainda que na operação de financiamento de curto prazo, denominada em moeda inconversível, há um risco de preço expressivo, em razão da volatilidade da taxa de juros. No caso brasileiro, a possibilidade de descasamento entre o retorno das aplicações e o custo das captações deu ensejo ao aparecimento dos títulos públicos remunerado a taxas de juros repactuadas, 
diariamente, pela taxa do overnight, eliminando o risco de descasamento no seu carregamento. No caso das operações de crédito bancário a relevância desse risco fica evidente quando se considera o spread muito alto da taxa de juros ativa ante a passiva. Vale dizer, o risco elevado de variação da taxa de juros no período do empréstimo induz o intermediário financeiro a definir margens (spreads) muito altos, de maneira a se proteger de possível mudança na taxa de juros.

Diante das características assinaladas acima é possível entender por que não se desenvolveu no país o financiamento de longo prazo, como conseqüência da pouca efetividade da função reserva de valor da moeda local decorrente do pecado original e exacerbado por um passivo externo elevado e pelo baixo montante de reservas que determinaram a volatilidade da taxa de câmbio e ampliaram o patamar e a volatilidade das taxas de juros. A transmissão das características inerentes à inconversibilidade aos mercados locais via taxa de juros elevadas e voláteis acentua o risco da atividade financeira por excelência, o desdobramento de prazo, levando a uma alta preferência pela liquidez. Ante os riscos decorrentes dessa configuração, o risco jurisdicional tem caráter secundário. Diante disso, pode-se também inferir que em economias com essas características só é possível desenvolver um sistema de financiamento de longo prazo mediante mecanismos de direcionamento do crédito.

A substituição da moeda local por uma moeda conversível, na denominação das operações domésticas, não elimina os riscos referidos anteriormente. As taxas de juros até podem ser menores e os prazos dos títulos e empréstimos, maiores, pois para os investidores ou intermediários financeiros elimina-se o risco de preço decorrente da variação cambial. Mas, como as operações têm um lado doméstico, os demais riscos são exacerbados. Isso vale, por exemplo, para qualquer agente doméstico que emite dívida na moeda conversível mas cuja receita está em moeda local. Ou seja, amplia-se o currency mismatch.

Por fim, mas não por último, destaque-se que o atributo da inconversibilidade, embora intrínseco às moedas dos países periféricos, ganhou maior relevo na economia contemporânea em decorrência da crescente mobilidade de capitais. O ponto central é que a abertura financeira desses países não apenas explicita a inconversibilidade mas também acentua a instabilidade monetária, "de fora para dentro", com conseqüências significativas sobre o custo do crédito de curto prazo e a ausência de financiamento de longo prazo na moeda local.

Há uma terceira conseqüência da inconversibilidade da moeda entendida como a atrofia da sua função de reserva de valor, determinada pela volatilidade de seu valor externo: o não desenvolvimento nas economias periféricas de formas superiores de organização do capital em particular, a sua etapa financeira. Das várias dimensões relativas a essa atrofia a mais evidente, como observado por Cardoso de Mello (1997), é a ausência de um mercado de capitais desenvolvido. Ou seja, as economias periféricas, na sua maioria, carecem de um mercado de ações ou de títulos de dívida de magnitude e profundidade adequadas. Isso pode ser tomado 
como reflexo da baixa qualidade das moedas enquanto reserva de valor e, portanto, da sua incapacidade em expressar, de modo menos volátil, o valor dos ativos cujo padrão é, em última instância, a moeda reserva.

Em várias dessas economias, como nas asiáticas, o processo de centralização de capitais, como apontado por Singh (1995), foi realizado por vias político-administrativas sem o apoio ao mercado de capitais. Ao discutir o caso do Brasil, Tavares (1998) afirma que das três funções clássicas do sistema financeiro, a criação de crédito, a intermediação financeira e a centralização do capital, as duas primeiras tiveram, de um ou outro modo, desenvolvimento satisfatório, enquanto a última permaneceu atrofiada.

Referindo-se aos anos 1960 e 1970, durante a fase de restrições à abertura financeira e de repressão do sistema, a autora defende que foi possível realizar a tarefa de mobilização de recursos para financiar o desenvolvimento, em parte pelas instituições públicas e pelo direcionamento do crédito, mas não foi viável alcançar o objetivo de, na esfera da propriedade, concentrá-la e orientá-la para a esfera produtiva. Esta função foi realizada passivamente pelo Estado, que criou formas particulares de mobilização de recursos de longo prazo. Mas essas formas possuíam limitação intrínseca, pois mobilizou-se capital sem modificar, simultaneamente, a estrutura de propriedade preexistente.

O período recente, após 1990, durante o qual se processou uma expressiva centralização da propriedade, envolvendo, em parte, a aquisição de ativos estatais por empresas domésticas, é tratado por Miranda e Tavares (1999) como semelhante a fases anteriores. A realização da concentração, promovida pelo Estado, se deu de forma passiva, ou seja, as empresas não utilizaram esse processo para ampliar escalas de produção ou avançar na separação entre gestão e propriedade, mantendo seu perfil rentista e patrimonialista.

\section{CONCLUSÕES}

O debate da inconversibilidade monetária numa economia globalizada, olhado de um ponto de vista da periferia, realizado neste texto, sugere implicações cruciais para os países em desenvolvimento. A primeira é a de que a inconversibilidade tem uma dimensão internacional irredutível, o denominado original sin, oriunda da constituição hierarquizada do sistema monetário internacional. Mas isso não é tudo. $\mathrm{Na}$ ausência de políticas deliberadas para lidar com o problema, pode-se desenvolver um mecanismo de transmissão, de fora para dentro, capaz de enfraquecer as moedas locais suprimindo suas prerrogativas no âmbito doméstico.

As políticas postas em prática por um conjunto de países asiáticos em desenvolvimento para evitar os efeitos deletérios da inconversibilidade são conhecidas: acumulação de reservas na moeda-chave, produção sistemática de superávits em transações correntes, ambas com custos em termos de potencial de crescimento 
ou de consumo desses países, decorrente da acumulação de poder de compra não utilizado sob a forma de reservas mas com benefícios oriundos da criação de um espaço doméstico para a cumulação de capital, do qual faz parte a estabilidade monetária e cambial e o financiamento de longo prazo em moeda doméstica.

Em síntese, além dos vários problemas decorrentes da inconversibilidade, tais como a instabilidade macroeconômica e o risco elevado da intermediação financeira, há um terceiro, mais profundo: o caráter de representante geral da riqueza, atributo genérico da moeda, não é plenamente exercido. Como implicação temos que o processo de acumulação e concentração do capital, nessa moeda, está restrito aos processos produtivos, enquanto aqueles processos de concentração que ocorrem na esfera financeira, por meio da centralização, encontram-se bloqueados.

\section{REFERÊNCIAS BIBLIOGRÁFICAS}

ARIDA, P. (2003a). "Por uma moeda plenamente conversível”. Revista de Economia Política, v. 23, n. 3 (91), pp. 151-154, jul./set. São Paulo: Editora 34.

ARIDA, P. (2003b). “Ainda sobre conversibilidade”. Revista de Economia Política, v. 23, n. 3 (91), pp. 135-142, jul./set. São Paulo: Editora 34.

ARIDA, P., BACHA, E. \& LARA-RESENDE, A. (2004). "High interest rates in Brazil: conjectures on the jurisdicional uncertainty". Rio de Janeiro: Casa das Garças, (mimeo).

BELLUZZO, L. G. M. (1997) “O dinheiro e as metamorfoses da riqueza”. Em: Tavares, M.C e Fiori,J. L. Poder e dinheiro. Uma economia política da globalização. Rio de Janeiro: Vozes.

BELluZZO, L. G. de M. \& CARNEIRO, R. (2004). "O mito da conversibilidade". Revista de Economia Política, v. 24, n. 2, pp. 218-222, abr./jun. São Paulo: Editora 34.

BORDO, M. \& FLANDREAU, B. (2001). "Core, periphery, exchange rate regimes, and globalization”. NBER Working Paper, No 8584, November.

CARDOSO DE MELlO, J. M. (1997) Prólogo. Em: Tavares, M.C e Fiori,J. L Poder e dinheiro. Uma economia política da globalização. Petrópolis: Vozes.

COHEN, B. J. (1998). The geography of money. Ithaca Cornell University Press.

EICHENGREEN, B. \& HAUSMANN, R. eds. (2005). Other people's money - debt denomination and financial instability in emerging market countries. Chicago: The University of Chicago Press.

EICHENGREEN, B., HAUSMANN, R. \& PANIZZA, U. (2003) “Currency Mismatches, Debt Intolerance and Original Sin: Why They Are Not The Same and why it Matters". NBER Working Paper n. 10036.

FIORI, J. L. (1999) “Estados, moeda e desenvolvimento”. Em Fiori, J. L. (org.) Estados e moedas no desenvolvimento das Nações. Petrópolis: Vozes.

GILPIN, R. (1971) The poltics of transnational economic relations. International Organization, Special Issue, 25.

GOLDSTEIN, M; \& TURNER, P. (2004.) “Controlling currency mismatches in emerging markets". Washington DC: Institute for International Economics,

HERMANN, J. (2004) "Financiamento de longo prazo: revisão do debate e uma proposta para o Brasil.” Em Sicsú, J. et al Agenda Brasil. Rio de Janeiro: Editora Manole.

KINDLEBERGER C. P. (1973) The world in depression, 1929-1939. Berkeley, University of California Press. 
MEDEIROS, C. (2006) “A Economia Política da Integração Financeira e da Privatização na América Latina". (mimeo)

MIRANDA, J. C. \& TAVARES, M. C. (1999) “Brasil: estratégias de conglomeração”. Em Fiori, J. L. (org.) Estados e moedas no desenvolvimento das Nações. Rio de Janeiro, Vozes.

REINHART, C.; K. ROGOFF \& M. SAVASTANO (2003). "Debt intolerance". Brookings Papers on Economic Activity vol 1: 2003.

SCANDIUCCI Filho, J. G. (2000) "Hegemonia, Estados e Mercado nos arranjos de Bretton Woods." Campinas: IE/Unicamp, Tese de doutorado.

SERRANO, F. (2002) “Do ouro imóvel ao dólar flexível.” Economia e Sociedade, v. 11, n. 2, 2002. Campinas:IE/Unicamp

SINGH, A. (1995). "How did East Asia grow so fast? Slow progress towards an analytical consensus". Unctad Discussion Papers, 97, February. Geneve: UNCTAD.

TAVARES, M. C. \& BELLUZZO, L. G. (2004) “A mundialização do capital e a expansão do poder americano". Em Fiori, J. L. O poder americano. Petrópolis: Vozes

TAVARES, M. C. (1998) Ciclo e crise. Campinas, IE/Unicamp. Coleção 20 anos. Primeira edição de 1978.

WALTZ, K. N. (1959) Man, the State and War: a theoretical analysis. Nova York: Columbia University Press. 